\title{
Diagnosis of Helicobactor pylori in Bangladesh: Limited Options and Utility of Serologic Test
}

\author{
Rahman $\mathrm{MM}^{1}$, Rowshon $\mathrm{AHM}^{2}$, Rahim $\mathrm{S}^{3}$
}

\begin{abstract}
Helicobactor pylori ( $H$ pylori) is one of the commonest and most ancient chronic bacterial infection of mankind. Like other developing countries, the prevalence of $\mathrm{H}$ pylori is very high in Bangladesh. More than $80.0 \%$ children become infected with $H$ pylori by the age of 6-9 years ${ }^{1}$ and $92.0 \%$ adult population are seropositive for $H$ pylori in Bangladesh $^{2}$. H pylori infection is a common and curable cause of dyspepsia, peptic ulcer diseases and few upper GI malignancies. Approximately $17.0 \%$ of infected patients develop peptic ulcer, and one quarter of such patients experience an ulcer complication ${ }^{3}$. In a community based endoscopic survey among adult population, the prevalence of peptic ulcer disease was found to be $15.6 \%$ in Bangladesh ${ }^{4}$.
\end{abstract}

For effective treatment of $H$ pylori infection, accurate diagnosis is important. $H$ pylori can be diagnosed by invasive techniques using endoscopy and biopsy or by non invasive techniques. The invasive tests are histological examination, culture and rapid urease test. The non invasive tests are urea breath test (UBT), stool antigen test (SAT) and serology. UBT and SAT detect active infection and are called active test whereas serology is called passive test. The choice of the test depends on local availability, clinical setting, pretest probability of infection, upper gastrointestinal bleeding, and use of antisecretory drugs, bismuth or antibiotics and cost of the test. So choosing the 'right test' at a particular situation demands rationality. Dyspepsia is a common problem in the general population and clinical practice. Test-and-treat, empiric acid suppressive therapy and prompt endoscopy are common strategic approaches of management for patients of uninvestigated dyspepsia. Testand treat strategy implies to test all dyspeptic patients by non-invasive methods and to treat positive cases for eradication of $H$ pylori. It offers cure for $H$ pylori positive subjects and minimizes unnecessary endoscopy and thus avoid cost, inconvenience and discomfort in a number of subjects. Empiric acid suppressive therapy means treating patients with proton pump inhibitors or $\mathrm{H}_{2}$ Receptor Blockers empirically. It does not cure $H$ pylori infection and particularly in those with underlying ulcer disease results in frequent relapse of ulcer symptoms.
Most regional and international guidelines have recommended test-and treat strategy for dyspeptic patients of population with high prevalence $(>10 \%-20 \%)$ with $H$ pylori infection in the absence of alarm features. Patients with alarm features and above the local age cut-off point of gastric cancer and all dyspeptic patients will have to be endoscoped $^{5-9}$. For Bangladesh, 50 years has been taken as the age threshold for endoscopy ${ }^{10}$. Considering the high prevalence of $H$ pylori in Bangladesh, the preferred strategy should be non-invasive test-and-treat compared to empiric anti-secretory therapy and costly initial endoscopy. But this needs evaluation of available reliable non invasive tests and cost effectively. The preferred methods of diagnosing $H$ pylori by non-invasive method in pre and post treatment settings are UBT and SAT9. But these tests are not commercially available in Bangladesh. So, the only non-invasive test to detect $H$ pylori available in Bangladesh is serologic test. Unfortunately, this test is also not uniformly available throughout the whole country. Serologic test detects $H$ pylori specific IgG antibodies in serum. Positive serological test means either the patient is infected at the time of the test, or the patient was once infected but, by the time, the test is done infection has resolved or the test is detecting non-specific cross-reacting antibodies. The serologic tests are simple and cheap. Overall, the sensitivity is between $90.0 \%$ and $97.0 \%$ and the specificity is between $50.0 \%$ and $96.0 \%{ }^{11}$. However, its use needs proper evaluation. Firstly, diagnostic accuracy of various commercial serology-kits differs substantially. This is because of the antigenic differences of strains of H pylori in different group of population in the world. So, serology assays using antigen from one part of the world may not be appropriate when applied to another population. Therefore, every serologic test should be validated locally before routine use and the preferred method should be ELISA not ICT. Secondly, the positive predictive value of serologic test is greatly influenced by local prevalence of $H$ pylori; it is high in high and low in low prevalent population. In a study in Bangladesh, the sensitivity, specificity, positive predictive value and negative predictive value of ELISA based serologic test were found to be $97.0 \%, 43.0 \%, 83.0 \%$ and $82.0 \%$

1. Dr. Mohammed Masudur Rahman, Assistant Professor, Department of Gastroenterology, Shaheed Suhrawardy Medical College, Dhaka

2. Professor Dr. A. H. M. Rowshon, Professor and Head, Department of Gastroenterology, Shaheed Suhrawardy Medical College, Dhaka

3. Dr. Sayeda Rahim, Associate Professor, Department of Gastroenterology, Shaheed Suhrawardy Medical College, Dhaka

Correspondence: Dr. Mohammed Masudur Rahman, Assistant Professor, Department of Gastroenterology, Shaheed Suhrawardy Medical College, Sher-E-Bangla Nagar, Dhaka, Bangladesh; Email: dr.masud47@yahoo.com; Mobile: +8801711544368 
respectively ${ }^{12}$. Thirdly, serologic test is not useful as a test of eradication. This is simply because the IgG anti H pylori antibodies remain detectable even many years after successful eradication of $H$ pylori. So, serologic test can be used to detect evidence of $H$ pylori infection any time before and is a useful tool for population survey. It is to mentioned that, serology test has got importance in certain clinical conditions; these are bleeding peptic ulcers, extensive gastric atrophy, MALT lymphoma and current use of PPIs, bismuth or antibiotics. In these conditions intragastric bacterial density is low which reduces the accuracy of other noninvasive and invasive diagnostic tests.

Invasive tests to detect $H$ pylori require endoscopy and biopsy. Endoscopy of upper GIT is recommended to be done in patients aged more than 50 years, in presence of alarm features or in patients not responding to initial empiric therapy. The advantage of endoscopy is to diagnose organic disease in addition to taking biopsy specimens for histology, rapid urease testing, brush cytology and also for culture of $H$ pylori. Culture and sensitivity for $H$ pylori is done only in advanced centre and not commercially available in Bangladesh. Rapid unease tests (RUT) are easy, cheap and are reasonably accurate. The sensitivity of RUT is about $90.0 \%$ to $95.0 \%$ and specificity is $95.0-100.0 \%{ }^{11}$. The sensitivity is affected by the number of bacteria present in the biopsy and the minimum number is $10^{4}$. Low sensitivity and specificity are also reported in patients taking proton pump inhibitors or antibiotics post-treatment, bleeding patients and in patients with achlorhydria. This test is not advised in these clinical settings. For histological diagnosis, adequate exposure and training in this area of detection of $\mathrm{H}$ pylori are very much essential but histopathologists with this experience are not adequate in our country.

Though the prevalence of $H$ pylori in Bangladesh is very high, there are limited options for its diagnosis. Only noninvasive diagnostic test available is serologic test which has high positive predictive value in Bangladesh. So, only locally validated kit for ELISA is advised to be done for accurate diagnosis of $H$ pylori infection in a specified situation like population survey but not in clinical conditions to take decision for treatment.[J Shaheed Suhrawardy Med Coll, 2013;5(1):1-2]

\section{References}

1. Mahalanabis D, Rahman MM, Sarker SA, Bardhan PK, Hildebrandet $\mathrm{P}$, Beglinger C, et al. Helicobactor pylori infection in the young in Bangladesh: Prevalence, Socioeconomic and Nutritional Aspects. International J Epidemiol 1996;25: 894-898.

2. Ahmad MM, Rahman M, Rumi MAK, et al. Prevalence of Helicobacter pylori in asymptomatic population - a pilot serological study in Bangladesh. Japan J Epidemiol 1997; 7: 251-54

3. Tytgat GNJ, Lee A, Graham DY et al. The role of infectious agents in peptic ulcer disease. Gastroenterol Internat 1993; 6: 76-89

4. Hasan M, Azad khan AK, Roy PK, Aziz S, Huq KM, Ali SMK et al.Peptic Ulcer in Bangladesh. BMRC Bulletin 1987; 13:29-42

5. Talley NJ, Vakil N, the Practice Parameters Committee of the American College of Gastroenterology. Guidelines for the management of dyspepsia. Am J Gastroenterol. 2005;100:2324-37.

6. Talley, N.J., Vakil, N.B. and Moayyedi, P. American Gastroenterological Association technical review on the evaluation of dyspepsia. Gastroenterology 2005;129: 1756-1780.

7. Veldhuyzen van Zanten S, Bradette M, Chiba N, Armstrong D, Barkun A, Flook N, et al. Evidence-based recommendations for short- and longterm management of uninvestigated dyspepsia in primary care: an update of the Canadian Dyspepsia Working Group (CanDys) clinical management tool. Can J Gastroenterol. 2005;19:285-303.

8. Dyspepsia: a national clinical guideline, Scottish Intercollegiate Guidelines Network. www.sign.ac.uk/pdf/sign68.pdf. Updated March 2003. Accessed Apr 2010.

9. Malfertheiner P, Megraud F, O'Morain CA, Atherton J, Axon Anthony TR, Bazzoli F. Management of Helicobacter pylori infection -the Maastricht IV/ Florence Consensus Report. Gut 2012;61:646-664.

10. MiwaH, Ghoshal U C, Fock K M, Gonlachanvit S, Gwee K A, Ang T $\mathrm{L}$, ChangF $\mathrm{Y}$ et al. Asian consensus report on functional dyspepsia. J Gastroenterol Hepatol. 2012;27: 626-64.

11. Ricci C. Diagnosis of Helicobacter pylori: Invasive and non-invasive tests. Best Practice \& Research Clinical Gastroenterology 2007; 21: 299-313. 12. Rahman SHZ, Azam M G, Rahman M A, Arfin MS Alam, M M, Bhuiyan T M, Ahmed N, Rahman M, Nahar S, Hassan MS. Non-invasive diagnosis of $H$ pylori infection: Evaluation of serological tests with and without current infection marker CIM. World J Gastroenterol 2008 ; 14(8): 1231-1236. 